\title{
Entamoeba coli
}

National Cancer Institute

\section{Source}

National Cancer Institute. Entamoeba coli. NCI Thesaurus. Code C122295.

A species of commensal parasite in the class Archamoebae. E. coli is considered nonpathogenic. 